\title{
Effect of Doping on Electrical Properties of Nickel Oxide (NPs) Prepared by Pulse Nd-Yag Laser Deposition Method
}

\author{
Rasha Hamid Ahmed \\ University of Tikrit / College of Education for Pure sciences
}

Received 12-03-2021, Accepted 10-05-2021, Published 20-06-2021.

DOI: $10.52113 / 2 / 08.01 .2021 / 130-134$

\begin{abstract}
In this study, nickel oxide (NPs) films were produced by doping each element with $2 \%$ zinc, tin, iron, cobalt and magnesium. pulsed laser deposition was used to deposit them on glass substrates, and we used a pulsed Nd-YAG laser with a wavelength of $1064 \mathrm{~nm}$. All the films were annealed with one temperature $(573 \mathrm{k})$. The electrical properties of the prepared films were studied, such as the continuous electrical conductivity and activation energy, and we found that increasing the temperature increases the electrical conductivity values Also, the value of the electrical conductivity and the activation energy change according to the type of added doping. We also discovered many activation energy values in the temperature ranges of $(308 \mathrm{~K}-428 \mathrm{~K})$, and observed the conduct of nanoparticle oxide doping with various metals at these temperatures.
\end{abstract}

Keywords: Doping, Electrical properties, NiO (NPs), Pulsed laser deposition, Thin films .

\section{Introduction}

Nickel oxide is a green substance (pale green) that dissolves in alcohol and other solutions, and nickel oxide possesses an optical energy gap (3.6ev) and has a high electrical conductivity, as well as possesses ferromagnetic properties at low temperatures while acting as paramagnetic at high temperature [1,2]. Nickel oxide has a cubic, concentric crystal structure and the thin films formed from it are transparent [3] . Nickel oxide is used in electrode coloring devices, gas sensors, in catalysts, and in the manufacture of lasers $[4,5]$. Nickel oxide is considered one of the transparent conductive oxides and the most important characteristic of these oxides is the electrical conductivity, which increases with increasing temperature, as well as the electrical conductivity of transparent conductive oxides increases when impurities are added, as well as it has electrical and optical properties that are very important for its high transparency and electrical conductivity [6,7] . There are different physical and chemical deposition techniques, including the pulsed laser deposition method [8]. The pulsed laser deposition method is one of the best and cheapest techniques for deposition of semiconductors, metals and their oxides. Pulsed laser deposition is usually preferred to use high-energy laser pulses $[9,10]$.

In this work, we study the effect of doping with different metals (zinc, tin, iron, cobalt and magnesium) on the electrical properties of nickel oxide(NPs) prepared by pulsed laser deposition technique. These elements were specifically chosen because their oxides are of the n-type, unlike nickel oxide, as it is known that they are of the p-type. 


\section{Experimental}

Thin films of doping nanoparticle oxide ( $\mathrm{Zn}, \mathrm{Sn}, \mathrm{Fe}, \mathrm{Co}, \mathrm{Mg}$ ) were deposited with a doping rate of $2 \%$ for each material, and the purity of all materials was (9999.99\%) and all nanomaterials were nanomaterials. It was deposited on glass substrates at room temperature by pulsed laser deposition. The targets were prepared by mixing nickel oxide (the base material) with $2 \%$ of ( $\mathrm{Zn}, \mathrm{Sn}, \mathrm{Fe}, \mathrm{Co}, \mathrm{Mg}$ ) and each mixture was pressed using a hydraulic press type (specac). With a pressure of 6 tons for 10 minutes, we had discs with a diameter of $1.3 \mathrm{~cm}$. The target

\section{Results and Discussion}

The direct electrical conductivity study was Conducted as a function of temperature for the nanosynthetic nickel oxide films dpoing with ( $\mathrm{Zn}, \mathrm{Sn}, \mathrm{Fe}, \mathrm{Co}, \mathrm{Mg}$ ) because the conductivity of semiconducting materials increases with increasing temperature, so it has a great effect on the mobility of charge carriers, their concentration and their transfer through the medium.

The readings of the film resistance $(\mathrm{R})$ were recorded for the range $(308 \mathrm{~K}-428 \mathrm{~K})$, and by knowing the dimensions of the film, the resistivity $(\rho)$ was calculated according to the following equation $[2,11]$ :

$\rho=\mathrm{RA} / \mathrm{L}$

where ( A) is Section area , (L) is Slide length.

The direct electrical conductivity $\left(\sigma_{D C}\right)$ is calculated from the be inverted of the resistivity:

$\sigma=\mathrm{L} / \mathrm{RA}$ was positioned in front of a Nd-YAG pulsed laser with a wavelength of $1064 \mathrm{~nm}$ and a frequency of $6 \mathrm{~Hz}$, the laser was shed at a 45-degree angle, the laser energy was $300 \mathrm{mj}$, and the number of pulses was 200. Then, annealing was performed for all films at a temperature of $573 \mathrm{k}$ for one hour. The heating electrical properties were measured to find the change in the resistance of the film with the temperature within the range (308428k) using the electrical circuit with a sensitive digital electric scale and an electric

oven.

then we drew the relationship between the electrical conductivity and the temperature, from the figures $(1,2,3,4,5)$. They are convergent inside the gap, which makes it need less energy to move and conduct electrical conductivity $[7,12]$. The conductivity logarithm $(\ln \sigma)$ was drawn as a function of temperature ( $\mathrm{T} / 1000)$ for the nickel oxide films doping with ( $\mathrm{Zn}, \mathrm{Sn}$, $\mathrm{Fe}, \mathrm{Co}, \mathrm{Mg}$ ) as shown in Figure (6). As for the activation energy (Ea), it was calculated from the tendency of The graphical relationship that we drew between $(\ln \sigma)$ and the inverted of the temperature ( $\mathrm{T} / \mathrm{1000})$ according to the following equation [2]:

$\mathrm{Ea}=$ Slope $* 0.08562$ 
As the value (0.08562) is found by dividing the Boltzmann constant $\left(\mathrm{k}_{\mathrm{B}}\right)$ by the charge of the electron (e) multiplied by 1000.

Table (1) shows the values of activation energy and direct conductivity for all the prepared films. As we have more than one activation energy, this means that there are two electrical conduction methods, one for low temperature ranges and the other for high temperature ranges [7]. The first activation energy at the temperature range $(308 \mathrm{k}-378 \mathrm{k})$ represents the process of carriers' transition through position energy levels in the energy gap, which suggests a high density of position energy levels in the energy gap, and the second activation energy at the temperature range (398k-428k) They result from the transport of carriers across granular boundaries by catalyzed thermal ion emission [6]. We also note that the value of the second activation energy is higher than the value of the first activation energy, and this may be due to the oxygen vacuums formed in the film, which catch by doping atoms, which leads to this high value, which is believed to be the sum of the energy of movement of the spaces and the Configuration energy associated with them [13] . As for the doping elements, as we note from all figures that each element has a different effect from the other, and there are large differences between the electrical conductivity and the activation energy by the difference in the doping element, and this is due to the type of metal, If it has a P-type or n-type conductivity, those that have a negative conductivity the electrons will be the charge carriers the majority, and this in turn will increase the conductivity, as we can see when adding iron (Figure 3), as the doping here increased of charge carriers [6]. When the conductivity is of the p-type, the gaps will be the majority charge carriers and the electrons are the minority charge carriers $[6,7]$.

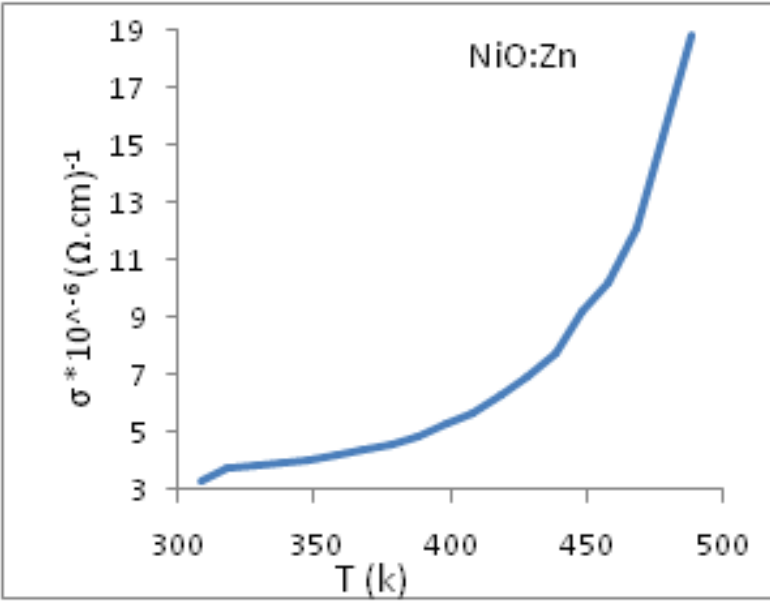

Figure (1) The conductivity $(\sigma)$ as function of temperature (T) for the Thin Film NiO: $\mathrm{Zn}(2 \%)$

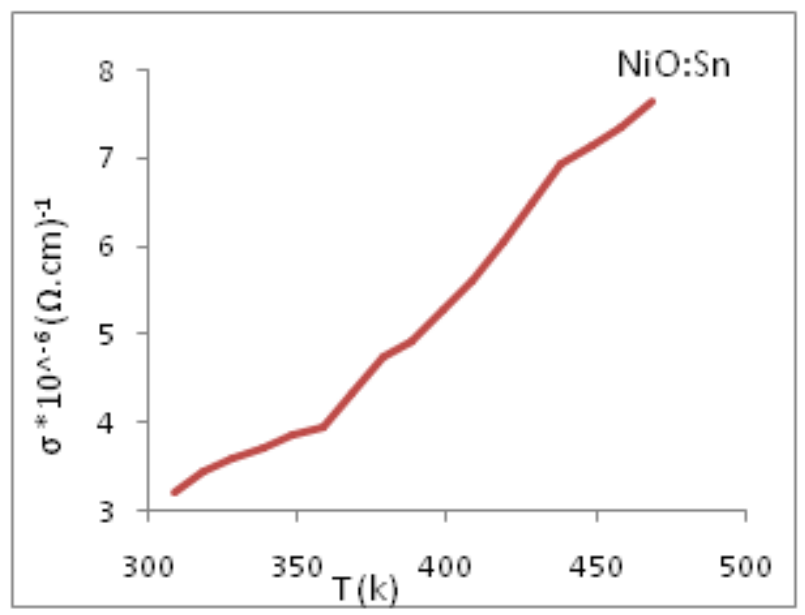

Figure (2): The conductivity $(\sigma)$ as function of temperature (T) for the Thin Film NiO: $\mathrm{Sn}(2 \%)$

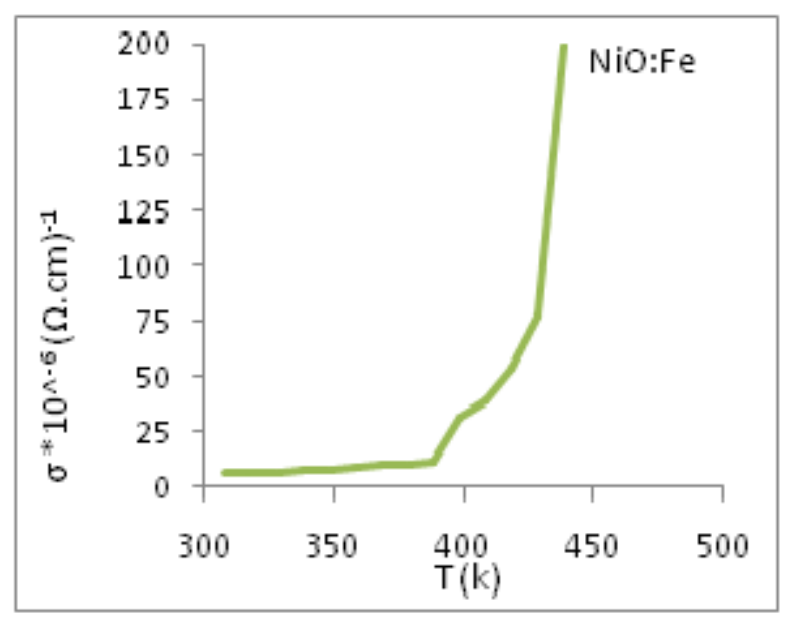

Figure (3): The conductivity $(\sigma)$ as function of temperature (T) for the Thin Film NiO: $\mathrm{Fe}(2 \%)$ 


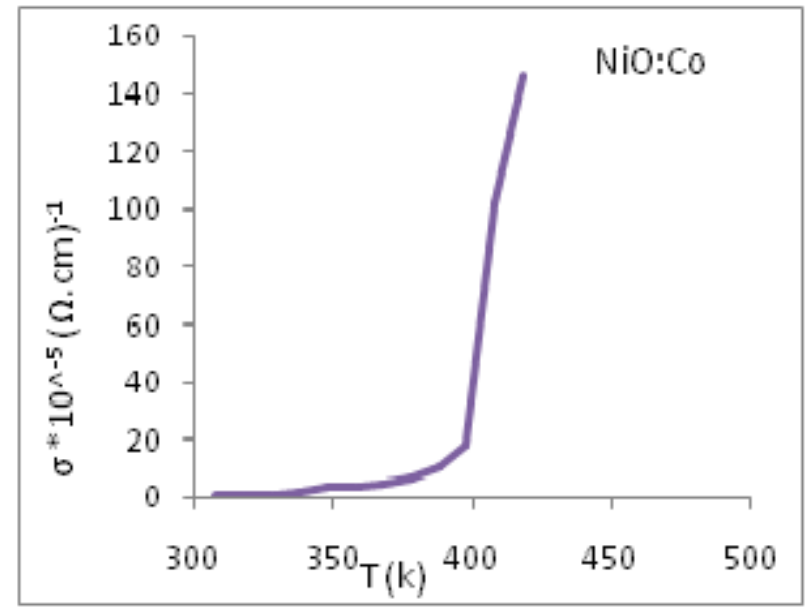

Figure (4): The conductivity $(\sigma)$ as function of temperature (T) for the Thin Film NiO: $\mathrm{Co}(2 \%)$

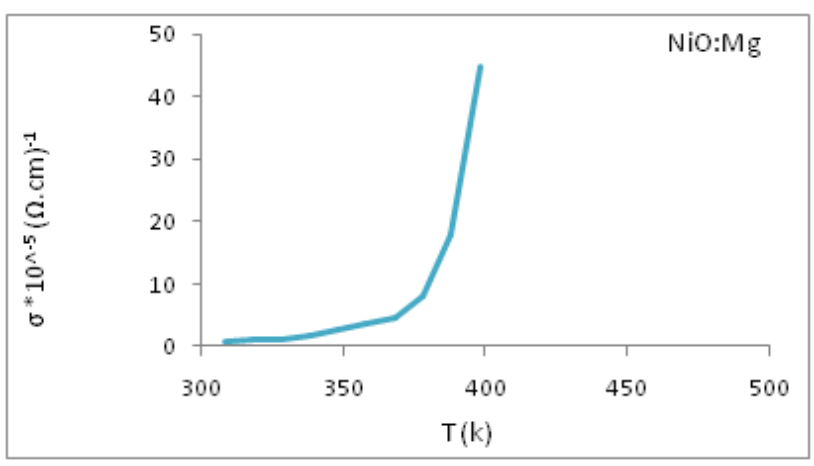

Figure (5): The conductivity $(\sigma)$ as function of temperature (T) for the Thin Film NiO: $\mathrm{Mg}(2 \%)$

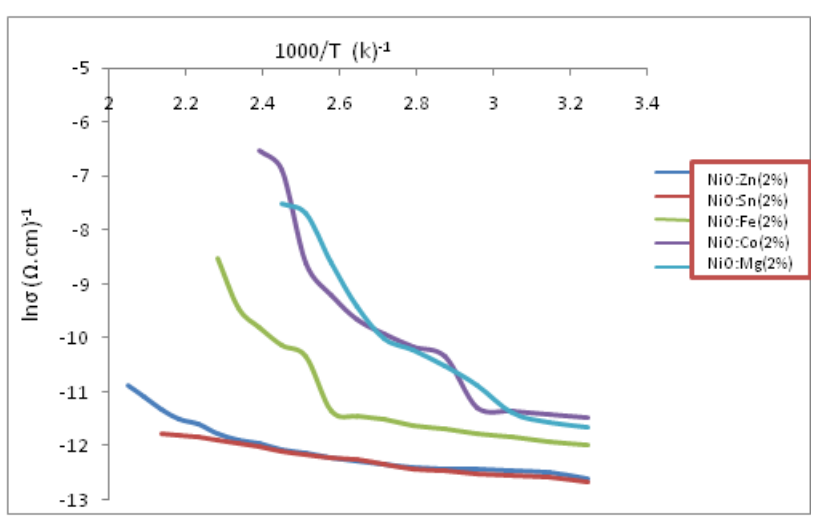

Figure (6): The $(\ln \sigma)$ as Function to $(1000 / \mathrm{T})$ for the Thin Films NiO: with $2 \%(\mathrm{Zn}, \mathrm{Sn}, \mathrm{Fe}, \mathrm{Co}, \mathrm{Mg})$

\section{Conclusion}

1- The pulse laser deposition method is a successful and easy method for obtaining thin films.

2- The process of doping of nickel oxide (NPs) with iron, cobalt and magnesium gave a direct high electrical conductivity.

3- The possibility of obtaining more than one activation energy.

4- Direct electrical conductivity increases with increasing temperature, and it is characteristic of semiconductor materials.

5- The values of direct electrical conductivity within the studied thermal range approximate to the known values of semiconductors.

Table (1) $\sigma_{\mathrm{DC}}$ and Ea for different temperatures For nickel oxide films Doping with different elements

\begin{tabular}{|c|c|c|c|c|}
\hline Sample & $\begin{array}{c}\sigma \text { at } \\
(308 \mathrm{k}) \\
* 10^{-6} \\
(\Omega \mathrm{cm})^{-1}\end{array}$ & $\begin{array}{c}\sigma \text { at } \\
(413 \mathrm{k}) \\
(\Omega \mathrm{cm})^{-1}\end{array}$ & $\begin{array}{c}(308- \\
378) \mathrm{k}\end{array}$ & $\begin{array}{c}(398- \\
428) \mathrm{k}\end{array}$ \\
\cline { 4 - 5 } & 3.36 & $1.88^{*} 10^{-5}$ & 0.045 & $\mathrm{Ea}_{2}(\mathrm{ev})$ \\
\hline $\begin{array}{c}\mathrm{NiO}: \\
2 \% \mathrm{wt} \mathrm{Zn}\end{array}$ & 3.2 & $7.65^{*} 10^{-5}$ & 0.057 & 0.099 \\
\hline $\begin{array}{c}\mathrm{NiO}: \\
2 \% \mathrm{wt} \mathrm{Sn}\end{array}$ & 6.28 & $1.99 * 10^{-4}$ & 0.074 & 0.42 \\
\hline $\begin{array}{c}\mathrm{NiO}: \\
2 \% \mathrm{wt} \mathrm{Fe}\end{array}$ & 10.3 & $1.45^{*} 10^{-3}$ & 0.26 & 1.47 \\
\hline $\begin{array}{c}\mathrm{NiO}: \\
2 \% \mathrm{wt} \mathrm{Co}\end{array}$ & 8.7 & $5.42^{*} 10^{-4}$ & 0.31 & 0.79 \\
\hline $\begin{array}{c}\mathrm{NiO}: \\
2 \% \mathrm{wt} \\
\mathrm{Mg}\end{array}$ & & & & \\
\hline
\end{tabular}




\section{References}

[1] A.Habeeb , S. Hasson , 2010 , Building a thermochemical spraying system to prepare solid materials in the form of thin films And the study of the physical properties of the prepared materials , Journal of Kufa - Physics Vol.2, no.2, pp. 12-20.

[2] H. Thyab , A. Najem , 2017, The Effect of doping by $\mathrm{Fe}$ and $\mathrm{Sn}$ on the physical properties of Nickel oxide thin films prepared by Spin coating

Tikrit Journal of Pure Science, vol.22, no. 12 , pp. 91-97.

[3] F.shaker , N.Ali , 2016, The effect of copper doping on the structural properties and the optical power gap of membranes Nickel oxide nanoparticles prepared by colloidal solution method, Journal of university of Babylon for Pureand Applied Sciences, vol.24, no.6, pp. 1572-1584.

[4] O.Abed , S.Chiad , and A.Kamel, 2013 , Effect of Thickness on the Optical Parameters of NiO Prepared by Spray Pyrolysis Technique, Diyala Journal of Pure Sciences , vol.9 , no.3 , pp.54-63.

[5] A. Fadell ,2016 , Enhanced hydrogen gas sensitivity employing sputtered deposited $\mathrm{NiO}$ thin films, Iraqi Journal of Physics, Vol.14, no.30, PP. 150-157.

[6] Kh. Hamdi , H.Hadi, and H.Hamada, 2019 , Effect of Fe Doping on Structural and Electrical Properties of $\mathrm{CdO}$ Thin Films Prepared by Chemical Bath Deposition Technique, Journal of University of Babylon for Pure and Applied Sciences, Vol. 27, No. 6 , pp.378-385.

[7] J .saleh , 2018, Study the structural and optical properties of membranes Nickel oxide grafted with copper, , MSc, College of sciences , University of Martyr Hama .

[8] A.Hassan,Kh.Khashan , and J.Saimon , 2015, Perparation and Characterization of $\mathrm{NiO}$ Thin Films by PLD, Eng.\&Tech. Journal ,vol.33,no.1,pp.52-60.
[9] T.Abd alabas , Gh.Aldahash , and W.Abd aldayem, 2015, Effect of laser parameters on compositional properties of sulfide films Lead prepared by pulse laser deposition method ,ResearchGate Journal Al-Baher , vol.2,no.3 and4,pp.99-108.

[10] A.Jawad , 2020 , Fabrication and characterization of (Nio) ${ }_{1-\mathrm{x}}(\mathrm{ZnO})_{\mathrm{x}}$ thin films for gas sensor applications, MSC, College of sciences, University of Krball.

[11] Reza . T, Electrical conductivity in polymer-Based composites: Experiments, Modeling and Applications,2019, Iran, p. 311.

[12] S. Salman , 2013, Effect of annealing and Mo , V and Ni Oxides as Doping Elements on Optical and Electrical Properties of BaTiO3 thin films , Diyala Journal of Pure Sciences, vol.9, no.1, pp.1-19.

[13] S.Jead, N.Fadel,and A.AL-Hassan ,2009, Electrical and Optical Properties SnOR2R:Sb at different doping concentrations, The third scientific conference, College of sciences, University of Baghdad, pp.2230-2238. 